\title{
A Cultura de Veraneio e a produção do espaço da Região Metropolitana da Baixada Santista (São Paulo, Brasil)
}

\section{The Summer Culture and the space production of the Metropolitan Region of Baixada Santista (São Paulo, Brazil)}

\author{
Maria Angela de Abreu Cabianca (CABIANCA, M. A. de A.) \\ Luis Henrique de Souza (SOUZA, L. H. de) ${ }^{* * *}$
}

\begin{abstract}
RESUMO - Este estudo se propõe a examinar os impactos do fenômeno "Cultura de Veraneio" sobre a configuração territorial do trecho do litoral paulista correspondente à Baixada Santista (São Paulo, Brasil). A área em estudo configura uma região metropolitana que engloba os municípios de Bertioga, Guarujá, Cubatão, Santos, São Vicente, Praia Grande, Mongaguá, Peruíbe e Itanhaém. A "Cultura de Veraneio" é compreendida neste contexto como o costume de passar o verão fora do domicílio habitual. A partir de pesquisa documental e elaboração de mapas, baseados em dados obtidos entre 2010 e 2014, que possibilitaram a comparação entre os imóveis ocupados pela população residente e a população flutuante, foi possível notar um padrão espacial decorrente da reinvenção da praia como espaço de lazer. Com o advento da Cultura de Veraneio, a função do litoral paulista se transformou e novas cidades surgiram ou foram reinventadas, não mais pelos processos econômicos que ali se desempenhavam, mas por vocação turística.
\end{abstract}

Palavras-chave: Turismo; Região Metropolitana da Baixada Santista; Cultura de Veraneio; Ocupação Territorial.

ABSTRACT - The purpose of this study is to examine the implications of the phenomenon called "Culture of Vacation" on the Baixada Santista territory, in São Paulo coast. The study comprises a metropolitan region that includes the municipalities of Bertioga, Guarujá, Cubatão, Santos, São Vicente, Praia Grande, Mongaguá, Peruíbe and Itanhaem. The "Culture of Vacation" is understood in this context as the behavior to spend the summer outside of the home. Based on documentary research and mapping (data base 2010-2014) that enabled the comparison between the dwellings occupied by the resident population and the floating population, it was possible to note a spatial pattern resulting from the reinvention of the beach as a leisure space. With the advent of the Culture of Vacation, the São Paulo coastline has changed and new cities have emerged or were reinvented, no longer due to economic processes, but as a tourist destination.

Key words: Tourism; Metropolitan Region of Baixada Santista; Vacation Culture; Territorial occupation.

\footnotetext{
* Formação: Bacharel em Ecologia pela Universidade Estadual Paulista (UNESP) e Geografia pela Faculdade de Filosofia, Letras e Ciências Humanas da Universidade de São Paulo (FFLCH-USP), Mestrado em Ecologia pelo Instituto de Biociências (IBio-USP), Doutorado em Saúde Ambiental pela Faculdade de Saúde Pública (FSP-USP). Atividade profissional: Docente dos cursos de Arquitetura e Urbanismo, Turismo, Hotelaria e Ciências Biológicas, e colaboradora do Programa de Pós-Graduação Stricto Sensu em Hospitalidade da Universidade Anhembi Morumbi. Endereço físico para correspondência: Rua Casa do Ator, 275. CEP: 04546-001, São Paulo - São Paulo/SP - Brasil. E-mail: maia.cabianca@gmail.com

** Discente do Curso de Arquitetura e Urbanismo da Universidade Anhembi Morumbi. Bolsista do Programa de Iniciação Científica do CNPq. Endereço físico para correspondência: Av. Roque Petroni Jr., 630 - Morumbi CEP: 04707-000 São Paulo - São Paulo/SP - Brasil. E-mail: luishenriquesouza@live.com
} 


\section{INTRODUÇÃO}

A "Cultura de Veraneio" - costume de passar o verão fora do domicílio habitual - apresenta uma intensa relação com a recente reinvenção da praia como espaço de lazer. Historicamente, o brasileiro vem se relacionando com a orla marítima como resultado de um misto de imaginários compostos pelos costumes de origem portuguesa, africana e indígena e, posteriormente, com a globalização, também de costumes provenientes do exterior (INSTITUTO POLIS, 2014).

O litoral brasileiro, que durante a colonização portuguesa desempenhava a função estratégica de escoamento de produção para a Europa, a partir do final do século XIX, foi gradativamente adquirindo uma nova forma de ocupação, relacionada a novas percepções deste espaço pela sociedade: a praia passa a ter importância como espaço de lazer (MINISTÉRIO DO TURISMO, 2010).

O resultado dessa concepção do espaço litorâneo é uma nova forma de ocupação, em que a permanência das pessoas é temporária, o que acarreta numa forte influência da população flutuante nos municípios que se desenvolveram a partir do crescimento da cultura de veraneio, assumindo assim uma vocação turística.

Neste estudo buscou-se avaliar as implicações do fenômeno "Cultura de Veraneio" na Região Metropolitana da Baixada Santista (RMBS), no litoral paulista, identificando fatores que caracterizavam tal cultura e suas influências na produção do espaço da RMBS, incluindo as características socioambientais e suas vulnerabilidades.

Após a apresentação da metodologia empregada neste estudo, serão tratados os aspectos históricos da ocupação do território da RMBS. Em seguida, discute-se o conceito e o processo de desenvolvimento da cultura de veraneio, característica no litoral de regiões tropicais. O item seguinte aborda as influências da cultura de veraneio na região estudada, apresentando mapas que demonstram que a ocupação dos imóveis pela população residente das cidades da RMBS vem se distanciando da orla, enquanto este espaço torna-se predominantemente ocupado por imóveis que servem à população flutuante. Ao final são feitas considerações sobre as transformações que a cultura de veraneio produziu no espaço da RMBS, como consequência do seu processo histórico de ocupação e das características socioeconômicas da região. 


\section{METODOLOGIA}

Empregou-se para este estudo a pesquisa bibliográfica e documental que possibilita a compreensão do processo inicial de ocupação da região estudada. Em seguida, foram gerados mapas que identificam, em diferentes trechos da RMBS, a população residente, diferenciando os espaços ocupados por imóveis destinados ao uso de veranistas. Os mapas foram produzidos no Laboratório do Curso de Arquitetura da Universidade Anhembi Morumbi, com o emprego do software QGIS, que provê visualização, edição e análise de dados georreferenciados.

Para compor a base cartográfica, com informações sobre a hidrografia, áreas de proteção ambiental, malha viária, delimitação e nomeação administrativa de municípios, foram utilizados os arquivos disponibilizados pelo INDE - Infraestrutura Nacional de Dados Espaciais e pelo Instituto Polis (2014), na plataforma Litoral Sustentável.

Para a espacialização dos dados referentes à concentração da população residente na RMBS, foram produzidos arquivos tipo cvs (Tabelas), com base no Censo Demográfico 2010, disponibilizados pelo Instituto Brasileiro de Geografia e Estatística - IBGE (2010). Para a produção dos mapas, foi realizado um cruzamento das tabelas que compõem a informação referente a "V002 - Moradores em domicílios particulares permanentes ou população residente em domicílios particulares permanentes", com a unidade territorial conhecida como "setor censitário" (IBGE, 2010).

A análise dos dados obtidos se fundamentou, ainda, na cartilha "Base de Informações do Censo Demográfico 2010: Resultados do Universo por Setor Censitário" (IPEA, 2012). Neste documento, comenta-se que:

[...] o setor censitário é a menor unidade territorial, formada por área contínua, integralmente contida em área urbana ou rural, com dimensão adequada à operação de pesquisas e cujo conjunto esgota a totalidade do Território Nacional, o que permite assegurar a plena cobertura do País (IPEA, 2012, p. 7).

Em muitos casos, os setores censitários estão desvinculados de unidades territoriais comuns nas leituras cartográficas, como acontece com o uso de quadras, distritos e malha urbana. 


\section{CONTEXTUALIZAÇÃO HISTÓRICA DA REGIÃO ESTUDADA}

Embora a criação da Região Metropolitana da Baixada Santista tenha sido proposta na década de 90, o território que engloba os municípios nela incluídos, segundo os sites da EMPLASA e da AGEM, já apresentava aspectos de regionalização, extrapolando as divisões administrativas municipais e compondo uma única região sob forte influência de Santos e São Vicente, cidades-metrópole que compõem o núcleo metropolitano.

Tendo em vista os primeiros anos de colonização, Santos e São Vicente podem ser consideradas, do ponto de vista histórico e econômico, como as mais importantes cidades do sudeste brasileiro (NEPO, 2009).

Segundo Bueno (1999), as relações de logística de exploração do território convergiram para a vila de São Paulo do Piratininga, a cidade-passagem, que fazia o intermédio entre o que era produzido e o que era extraído do extenso Planalto Paulista, e tinha como destino o Porto de Santos, no extremo oriente da Capitania de São Vicente. Tais relações fortaleceram a cidade de São Vicente, primeira cidade fundada por colonos portugueses, e, consequentemente, Santos, que desenvolveu sua vocação portuária e de ponto estratégico de escoamento de tudo que se retirava da Colônia Brasil (BUENO, 1999).

A figura 1, que representa a Capitania de São Vicente e a Vila de São Paulo de Piratininga, no Planalto Paulista, permite identificar graficamente a relação entre a Vila de São Paulo de Piratininga e as Capitanias de São Vicente e Santo Amaro. A distorção da perspectiva dá ao mapa contornos estratégicos de dominação e compreensão das redes mercantis que compunham o território.

Conforme mencionado por Bueno (1999), essas redes mercantis foram possibilitadas desde o início da colonização pela abertura da Trilha dos Tupiniquins, herança indígena conhecida como a mais antiga ligação entre São Vicente e a Vila de São Paulo de Piratininga. O autor cita ainda que a Trilha dos Tupiniquins compunha um trecho do grande Caminho do Peabiru, antigo trajeto utilizado pelos índios sulamericanos e que conectava o interior do continente, mais precisamente a região dos Andes, ao Oceano Atlântico. 


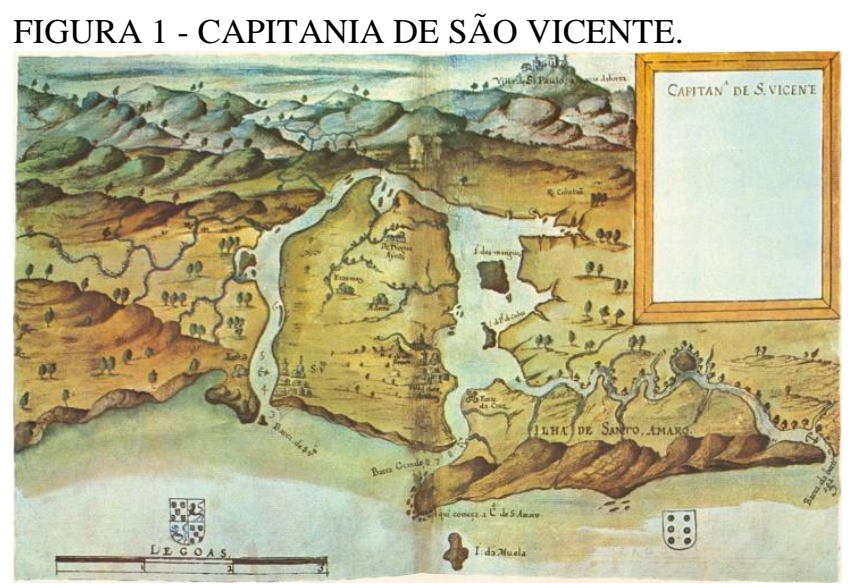

FONTE: Mapas Históricos Brasileiros, da enciclopédia Grandes Personagens da Nossa História, ed. Abril Cultural: São Paulo/SP, 1969.

Segundo Mendes (2005), a partir de 1554, a Trilha dos Tupiniquins seria substituída pelo Caminho do Padre José de Anchieta para o transporte de mercadorias por escravos e indígenas, tornando-se este caminho inviável para o transporte de açúcar e outros gêneros agrícolas produzidos no Planalto Paulista ao final do século XVIII.

Dadas as circunstâncias, em 1790 fez-se necessária a abertura da Calçada do Lorena, o primeiro caminho pavimentado que ligava o planalto a Santos, conforme relata Mendes (2005), acrescentando que o novo caminho possibilitava um aumento na eficiência do transporte e quantidade de produtos que eram escoados.

Com a crescente movimentação de cargas e pessoas entre o litoral e o planalto, impulsionada pela cultura do café, foi inaugurada, em 1844, a Estrada da Maioridade, nome que, segundo Mendes (2005), foi dado em alusão à emancipação de Dom Pedro II. O trajeto desta estrada cruzava alguns trechos da Calçada do Lorena.

A expansão da cultura cafeeira, inicialmente pelo sul do Rio de Janeiro e, posteriormente, no interior de São Paulo, tornou necessário o desenvolvimento de uma alternativa do porto do Rio de Janeiro, menos distante da região produtora.

Conforme menciona Mendes (2005), dois anos após a conclusão da Estrada da Maioridade, foi necessária sua interdição devido ao grande fluxo de tropeiros e muares, organizados em tropas de centenas de animais, que utilizavam o caminho para chegar ao litoral. O autor comenta que, ao longo do percurso, instalaram-se muitas pousadas que ofereciam leitos para os viajantes e pasto para as mulas, porém, a dificuldade do percurso encarecia o preço dos produtos, inclusive do café. 
O impulso dado pela Revolução Industrial, segundo Mendes (2005), somado à grande difusão e incentivo ao consumo do café nos países em processo de industrialização da Europa e da América do Norte, fizeram com que o produto alcançasse novos picos de produção no território nacional, proporcionando investimentos para a modernização dos processos de transporte e escoamento no território brasileiro. Destaca-se o papel da companhia The São Paulo Railway Company Limited (SPR), responsável pelo projeto da São Paulo Railway, a primeira estrada de ferro que ligou São Paulo ao Porto de Santos, conhecida como "A Inglesa", que foi, por muitos anos, uma alternativa exclusiva - em regime de monopólio - para transporte de cargas com destino ao porto de Santos (MENDES, 2005).

Com os novos investimentos, segundo o autor acima, o Porto de Santos vislumbrou seu auge, no mesmo período em que o estado de São Paulo presenciou um acréscimo demográfico impulsionado pela imigração de povos de várias procedências, estimulada pelo ciclo econômico do café, colaborando para o "embrionamento" de colônias que fundariam, mais tarde, novas cidades e povoados.

Desta forma, conforme verificou Mendes (2005), novas culturas foram introduzidas nas fazendas do litoral paulista, impulsionando a construção de novos eixos ferroviários de transporte. Destes se destacam a Linha Santos-Juquiá ou Linha das Bananeiras, construída pela Southern San Paulo Railway entre 1913 e 1915, ligando o trecho sul da Baixada Santista, onde se concentravam muitas fazendas que cultivavam bananas, ao porto de Santos. A estrada de ferro, segundo o autor, ainda se estendia até o estado do Paraná, promovendo uma conexão estratégica do litoral paulista com o sul do país, além de contribuir para a configuração econômica e política do que viria a se tornar o trecho sul da RMBS.

A pavimentação da Estrada da Maioridade, em 1917, associada à ascensão do poder de compra das classes capitalistas industriais paulistas inaugurou um novo período na história do estado de São Paulo (INSTITUTO POLIS, 2014). A gestão de Washington Luis, inicialmente na prefeitura municipal de São Paulo, depois no governo estadual e, a seguir, na presidência da República, fortaleceu a opção rodoviarista como modalidade de transporte, favorecendo, segundo Paula (2010), o boom automobilístico que se verificou nas décadas de 30 e 40, com a ascensão da burguesia industrial no Estado de São Paulo. 
A popularização dos automóveis particulares, o aquecimento da produção nacional, a maior facilidade e rapidez dos deslocamentos, proporcionadas pela pavimentação das estradas, são fatores que colaboraram com o surgimento do movimento pendular, em escala metropolitana, entre o planalto e o litoral, conforme sugerido pelo Instituto Pólis (2014). O referido trabalho sustenta ainda que a intensificação deste movimento em níveis inéditos até então, exigiram a construção da Rodovia Anchieta, concluída em 1947, conformando uma conexão viária metropolitana que incidiu na construção da Rodovia Imigrantes, concluída em 1976. As duas rodovias vieram a compor o sistema viário Imigrantes-Anchieta, que, associado a outros fenômenos econômicos e sociais, promoveu a consolidação da Cultura de Veraneio na Baixada Santista (INSTITUTO POLIS, 2014).

A nova forma de exploração do território da orla marítima da RMBS, favorecida pela acessibilidade que a malha viária possibilitou à região, trouxe um significado diferente a estas localidades, tanto para quem já vivia ali, quanto para os novos frequentadores, baseado nos hábitos e valores implícitos na Cultura de Veraneio, interferindo significativamente na paisagem litorânea, como se discute a seguir.

\section{A CULTURA DE VERANEIO}

A produção do espaço, como conceituou Lefebvre (1991), é resultado das diversas atividades humanas ao longo da história, que por sua vez são guiadas por fenômenos sociais, culturais e econômicos desempenhando direta influência sobre o meio natural. A constante mutabilidade do espaço não se dá apenas fisicamente. $O$ modo como é percebido, imaginado ou idealizado pelos homens também interfere na decorrência de suas modificações.

A paisagem pode ser considerada um dos elementos da produção e modificação do espaço, seja no plano físico ou no imaginário: é o resultado das atividades humanas, garantindo assim sua constante multifuncionalidade.

O modo como as pessoas percebem e utilizam o espaço é resultado de inúmeros fenômenos e é, portanto, passível de modificações e reinterpretações ao longo do tempo. Pode-se dizer que isso ocorre porque os elementos são meras repercussões de uma 
lógica de produção do espaço que se reconfigura, primeiramente, no campo das ideias, para depois se manifestar através de diversos agentes.

A reinvenção dos espaços praiais pela cultura de veraneio, enquadra-se no conceito de "espacialização social", que segundo Machado (2000, p. 202), constitui um “[...] processo social de construção do espaço, quer ao nível imaginário (construção de mitologias e representações coletivas sobre os lugares), quer ao nível da intervenção humana na paisagem".

Não muito diferente de outros povos nativos da América, os indígenas que ocupavam o território brasileiro cultivavam estrita relação com os elementos da natureza, sendo a água importante elemento dessa relação, incluindo aí os espaços praiais e os incontáveis cursos e corpos d'água que se distribuíam ao longo do território.

Segundo Hollanda (1982), muitas tribos do povo tupi, que inicialmente eram encontradas em toda extensão da faixa costeira brasileira, tinham como um dos meios de subsistência a pesca marítima. Diegues (1998, p. 1), em seu estudo antropológico dos povos marítimos e insulares, faz o seguinte comentário sobre este assunto:

A pesca, praticada pelos índios, é uma atividade anterior à chegada dos navegadores portugueses ao Brasil e peixes, crustáceos e moluscos eram parte importante de sua dieta alimentar. Os inúmeros sambaquis, depósitos de conchas encontrados em sítios arqueológicos ao longo do litoral atestam a importância da atividade da pesca e coleta.

O costume do banho diário constava dos hábitos dos povos indígenas, tendo sido, posteriormente, incorporado pelos europeus, mas não necessariamente numa relação direta com o advento da cultura de veraneio, como observa Ramos (2009, p. 49), ao afirmar que "como tudo na colônia, os códigos de conduta à beira-mar também foram importados de 'fora', ligados ao discurso médico europeu".

Embora a cultura do recreio seja observada em diversos aspectos do cotidiano indígena, como observa Ramos (2009), os banhos ao ar-livre tinham como princípio a higienização de seus corpos, sendo adotados pelos europeus como mecanismo de adaptação climática aos trópicos, se distanciando dos objetivos do turismo moderno em relação aos banhos de mar.

Segundo Hollanda (1982), a fisionomia mercantil da colonização portuguesa exprime-se tão sensivelmente no sistema de povoação litorânea ao alcance dos portos de embarque, quanto no fenômeno do desequilíbrio entre o esplendor rural e a miséria 
urbana. $\mathrm{O}$ autor afirma que, ao colonizador, não convinha que aqui se realizassem obras que não produzissem benefícios imediatos ou que acarretassem despesas ou prejuízos à metrópole (HOLLANDA, 1982, p. 107).

Conforme observado por Gaspar, (2004), o processo econômico e logístico que a produção e escoamento de produtos geraram nas cercanias do porto de Santos, é grande responsável pelo desenvolvimento econômico da região atraindo populações, fundando povoados e traçando novas rotas. Embora litorâneas, as primeiras estruturas urbanas fundadas pelos portugueses cultivavam uma relação limitada com as suas áreas de orla, conforme relatado pela autora supracitada:

\footnotetext{
No princípio, o Rio de Janeiro dos europeus ficava atrás da praia, porque só a terra lhes interessava. Vindos do mar para conquistá-la, os primeiros colonizadores deixavam as águas doces e salgadas do Novo Mundo entregues ao lazer de um povo brincalhão, que andava nu, e tinha os dias contados, mas vivia o presente como se fosse durar para sempre. (GASPAR, 2004, p. 31)
}

No entanto, ainda segundo relato de Gaspar (2004), a partir do séc. XIX, tal função foi gradualmente dividindo espaço com uma nova forma de ocupação, originada através do estabelecimento de novas percepções no imaginário social.

Fenômeno semelhante é observado por Schussel (2012), no processo de ocupação turística do território onde se localiza o Balneário de Camboriú (Santa Catarina, Brasil). A partir de 1758 começou a receber famílias da região próxima de Porto Belo e outras de origem alemã, atraídas pela fertilidade do solo e pelo clima. Mas a vocação turística da região, segundo a autora, surgiu:

\footnotetext{
A partir de 1920, com as primeiras casas de veraneio, de moradores provenientes do Vale do Itajaí, que trouxeram o hábito até então inexistente na região, de utilizar a praia como área de lazer e ali instalar a segunda residência da família” (SCHUSSEL, 2012, p. 111).
}

Segundo a mesma autora, a implantação da BR 101, na década de 1970, foi responsável pelo grande crescimento do número de turistas, "atraídos pela facilidade de acesso, inclusive turistas latino-americanos, principalmente argentinos e paraguaios que, desde então frequentam a região" (SCHUSSEL, 2012, p. 111).

A região litorânea de Fortaleza (Ceará, Brasil) teve processo de ocupação diferente dos mencionados anteriormente. Segundo Viana (2012), a orla do município permaneceu ocupada por atividades pesqueiras e portuárias, abrigando inclusive a 
população de retirantes da seca do sertão cearense até a década de 30 , quando a expansão populacional se dirige para áreas periféricas ao centro: "uma nova dinâmica a caminho do mar se dá a partir de transformações quanto à significação do sol, resultando da valorização social do sol e dos ambientes litorâneos” (VIANA, 2012, p. $41)$.

No litoral potiguar, o uso da praia para o lazer começou por Natal (Rio Grande do Norte, Brasil), no início do século XX, com a oficialização da Praia de Areia Preta como balneário, segundo relata Silva (2013), que informa também que, a partir das décadas de 1960/70, este uso se intensifica, quando as praias vizinhas a Natal, nos municípios de Parnamirim e Nísia Floresta começaram a ser ocupadas por residências secundárias. No entanto, o marco fundador do turismo no Rio Grande do Norte é identificado pelo referido autor como sendo a inauguração do Parque das Dunas/Via Costeira, na década de 1980.

Na Baixada Santista (São Paulo, Brasil) a aproximação entre a sociedade local e o litoral se dá de forma cada vez mais intensa a partir do final do século XIX e ganha dimensões bem maiores a partir da acessibilidade que essa região passa a ter, em consequência das conexões viárias que se instalaram a partir dos anos 40 , entre o litoral e a capital, conforme discutido pelo Instituto Pólis (2014).

A nova atividade de lazer que surgia na orla marítima de municípios litorâneos manifestava-se com a presença de carros de banho, como os da figura 2, que, segundo o site Novo Milênio, serviam para proteger o banhista da exposição ao sol no deslocamento até a beira do mar.

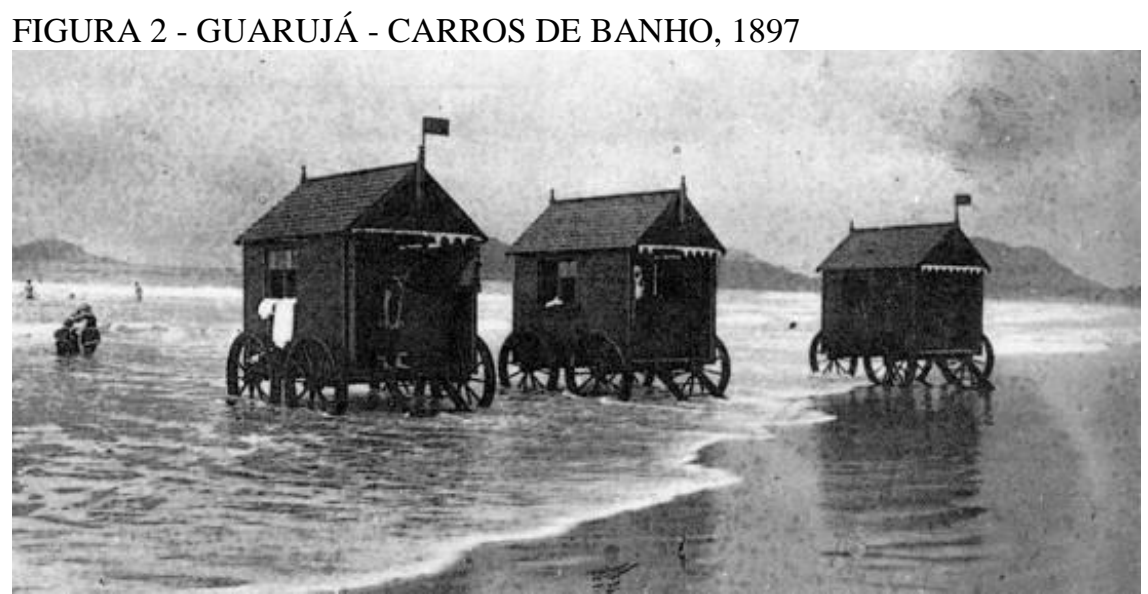

FONTE: Novo Milênio. Disponível em: <http://www.novomilenio.inf.br/guaruja/gfoto010.htm>. 
De acordo com Corbin (1989), atribui-se a reinvenção da praia aos novos costumes terapêuticos disseminados na Europa no século XVII pelo médico britânico Richard Frewin, segundo os quais a água salgada era comumente indicada por suas propriedades benéficas à saúde.

A nova forma de utilizar o espaço da orla marítima produziu mudanças na configuração do território dos núcleos urbanos que aí estavam estabelecidos.

Segundo Cruz (2003, p. 48), a extensa faixa litorânea do Brasil abriga três quartos da população brasileira e constitui também o espaço "onde o turismo ocorre de forma mais intensa e, consequentemente, mais significativa no que se refere ao processo de produção dos espaços urbanos".

A autora supracitada afirma que a construção histórica dos espaços litorâneos produziu uma divisão do litoral brasileiro, em que se observa um processo mais intenso de urbanização turística no litoral Nordeste e no litoral Centro-Sul do que no litoral Norte do país. Ainda em relação ao espaço produzido pela urbanização turística na costa brasileira, Cruz (2003, p. 49) observa que no litoral Centro-Sul, onde está mais concentrada a riqueza do país, ocorre "uma demanda solvável, capaz de arcar com os custos de uma residência de veraneio. Daí os condomínios de segunda residência ocuparem extensos trechos do litoral dos estados de São Paulo e do Rio de Janeiro".

A seguir são discutidas as influências que a cultura de veraneio exerceu na ocupação da Baixada Santista.

\section{AS INFLUÊNCIAS DA CULTURA DE VERANEIO NA BAIXADA SANTISTA}

Segundo o Instituto Polis (2014), entende-se como população flutuante o grupo de indivíduos que possuem um domicílio na RMBS, mas que não fazem uso dele continuamente, ou seja, não têm nela sua residência fixa. A população flutuante ocupa domicílios ocasionalmente, principalmente em datas festivas e feriados. Portanto, esses domicílios assumem a função de casas de veraneio.

Com o advento da "Cultura de Veraneio", a função do litoral se transforma e novas cidades surgem ou são reinventadas, não pelos processos econômicos que ali se desenvolviam, como em Santos e São Vicente, mas em decorrência da atratividade 
exercida pela praia e seu uso recreativo, como no caso de Bertioga, Mongaguá, Peruíbe e Itanhém.

A proximidade do litoral com a capital paulista e o aumento da frota de veículos possibilitaram a expansão do turismo sol e praia e, consequentemente, fizeram com que o mercado imobiliário na região litorânea expandisse o setor de construção, loteando e verticalizando a orla marítima para a ocupação ocasional por turistas, isto é, imóveis de segunda residência. Segundo Cruz (2003), o setor hoteleiro não resistiu à especulação do mercado imobiliário.

O eixo São Paulo/Rio de Janeiro, conforme comenta a mesma autora, está localizado na porção mais industrializada do território brasileiro e concentra a maior parte da riqueza produzida no país. Predomina aí, segundo ela, o fenômeno da segunda residência, que ganha maior destaque no conjunto das infraestruturas turísticas implantadas e em implantação, promovendo uma demanda de ocupação imobiliária de um público capaz de arcar com os custos de uma residência de veraneio, além das despesas da própria moradia em outra região do Estado e propiciando o surgimento de condomínios (horizontais ou verticais) de segunda residência, que ocupam extensos trechos da faixa costeira paulista.

Nas figuras 3, 4 e 5 pode-se observar a presença da população residente, evidenciada nos tons mais escuros da legenda, enquanto os tons mais claros representam as áreas ocupadas pela população flutuante, no trecho central da RMBS, no município de Praia Grande e no trecho sul da RMBS, respectivamente. Nestas imagens é possível identificar, através da distribuição da população flutuante e da população residente nos municípios na RMBS, a distinção dos espaços ocupados em consequência do crescimento da "Cultura de Veraneio". Nos municípios que integram a RMBS, a parcela flutuante supera a população residente, chegando a representar quase $80 \%$ da população total em alguns casos, de acordo com o censo demográfico do IBGE de 2010. 
FIGURA 3 - MAPA DA DISTRIBUIÇÃO DA POPULAÇÃO RESIDENTE NO TRECHO CENTRAL DA RMBS

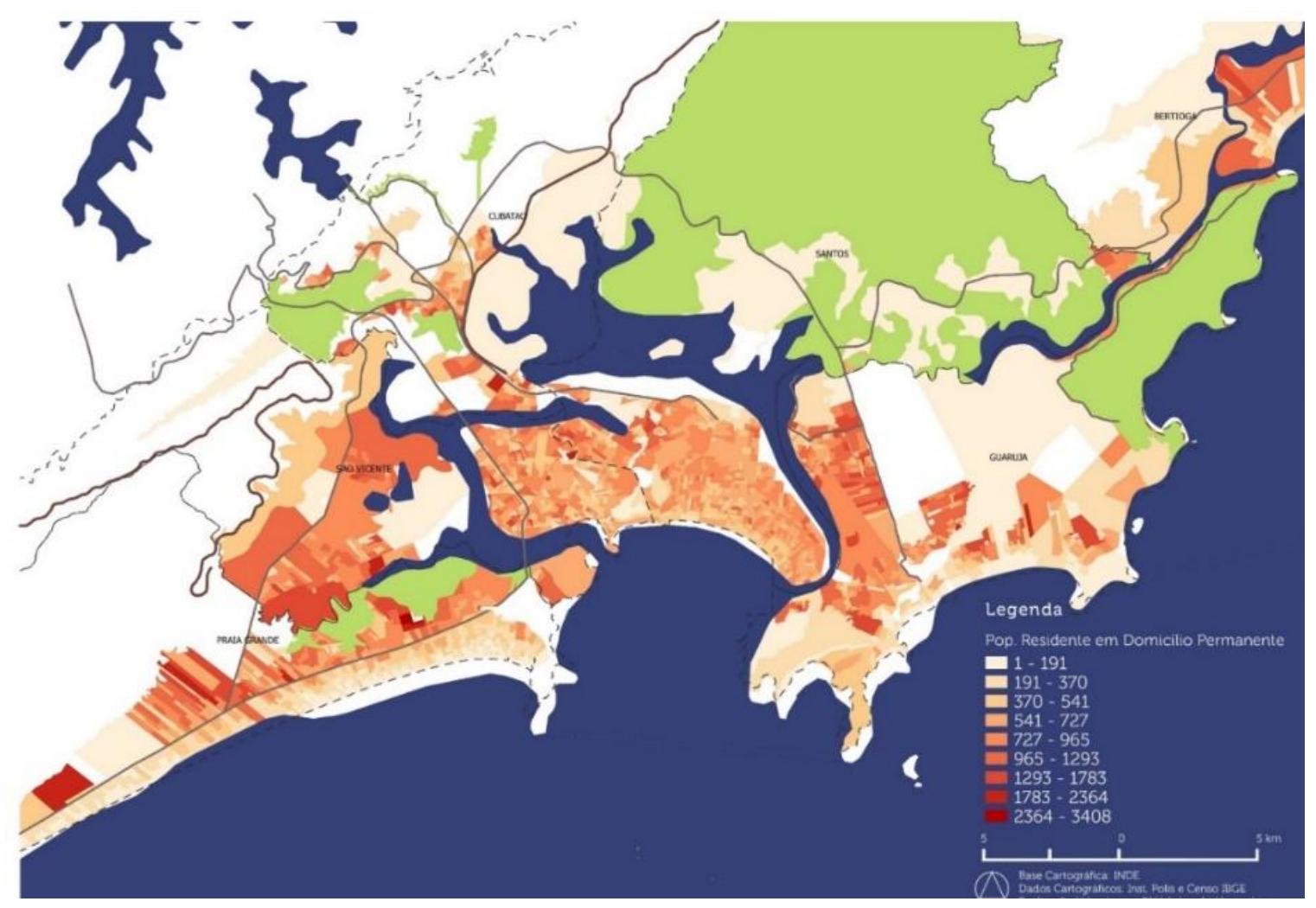

FONTE: Mapa produzido pelos autores.

O trecho Central da RMBS (FIGURA 3) compreende os municípios de Santos, São Vicente e Cubatão. Neste trecho a ocupação do território decorre de processos econômicos iniciais da história da região. A orla é valorizada por suas características cênicas e sua função recreativa, porém a localização do porto é um aspecto preponderante sobre a ocupação do território, sobretudo na área insular. As extensas áreas de manguezais, que estão presentes em todo o trecho sul do litoral paulista, encontram-se bastante degradadas no trecho Central da RMBS. Nestes espaços, a população residente dispõe de infraestrutura urbana precária, ocupando áreas desprezadas pelo mercado imobiliário ou áreas públicas situadas em regiões desvalorizadas (INSTITUTO PÓLIS, 2014). 
FIGURA 4 - MAPA DA DISTRIBUIÇÃO DA POPULAÇÃO RESIDENTE NO MUNICÍPIO DE PRAIA GRANDE

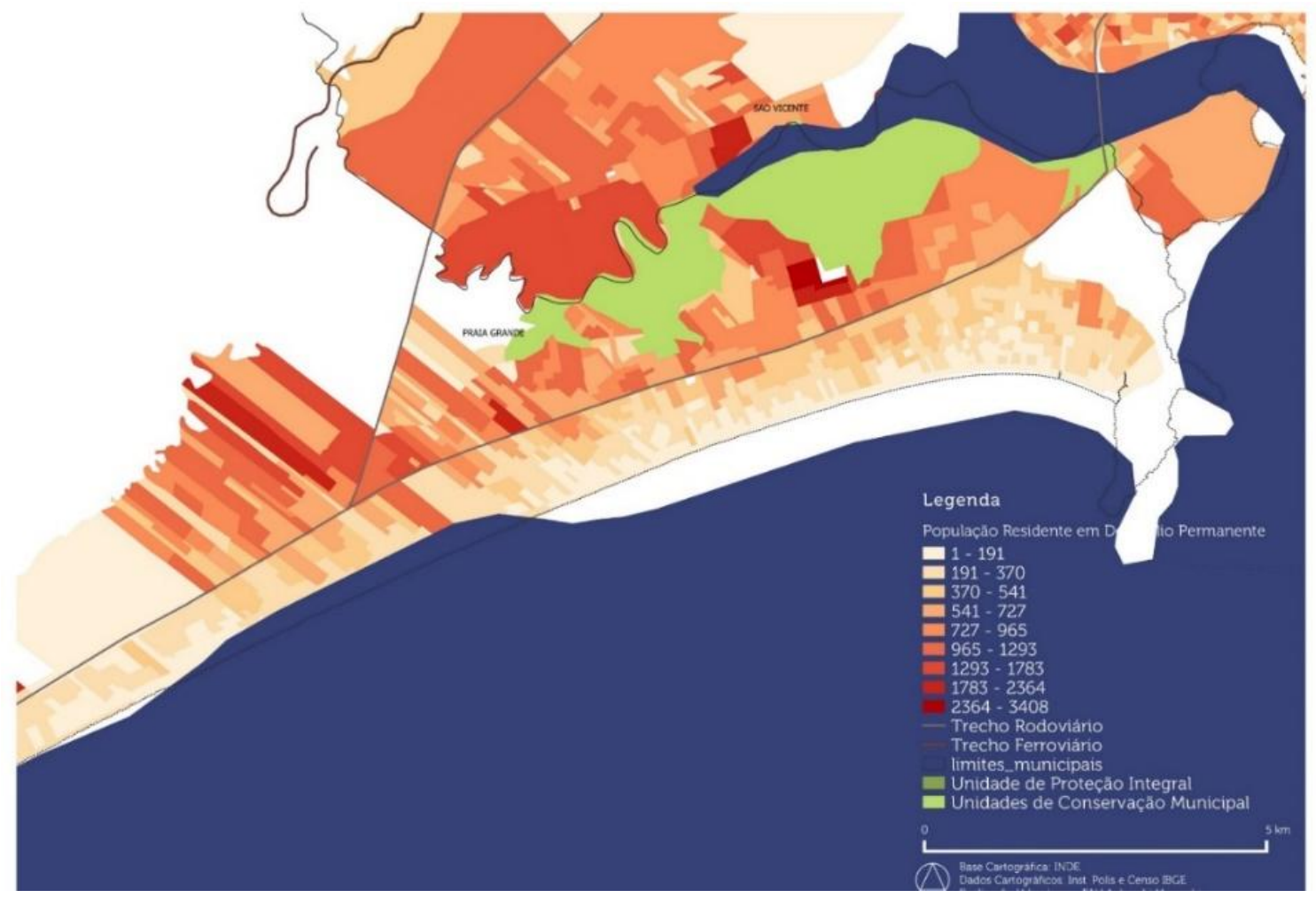

FONTE: Mapa produzido pelos autores

A distinção dos espaços ocupados pela população residente e aqueles ocupados pela população flutuante é bastante nítida no município de Praia Grande, como se observa na figura 4. Neste padrão espacial de ocupação, a linha que corresponde à rodovia Padre Manoel da Nóbrega - importante trecho viário que faz a conexão entre municípios do trecho Sul da RMBS - parece dividir o território, separando a área "mais turística" da área ocupada pela população residente. Este padrão se repete no restante do trecho Sul da RMBS, constituído também pelos municípios Mongaguá, Itanhaém e Peruíbe (FIGURA 5). 
FIGURA 5 - MAPA DA DISTRIBUIÇÃO DA POPULAÇÃO RESIDENTE NO TRECHO SUL DA RMBS

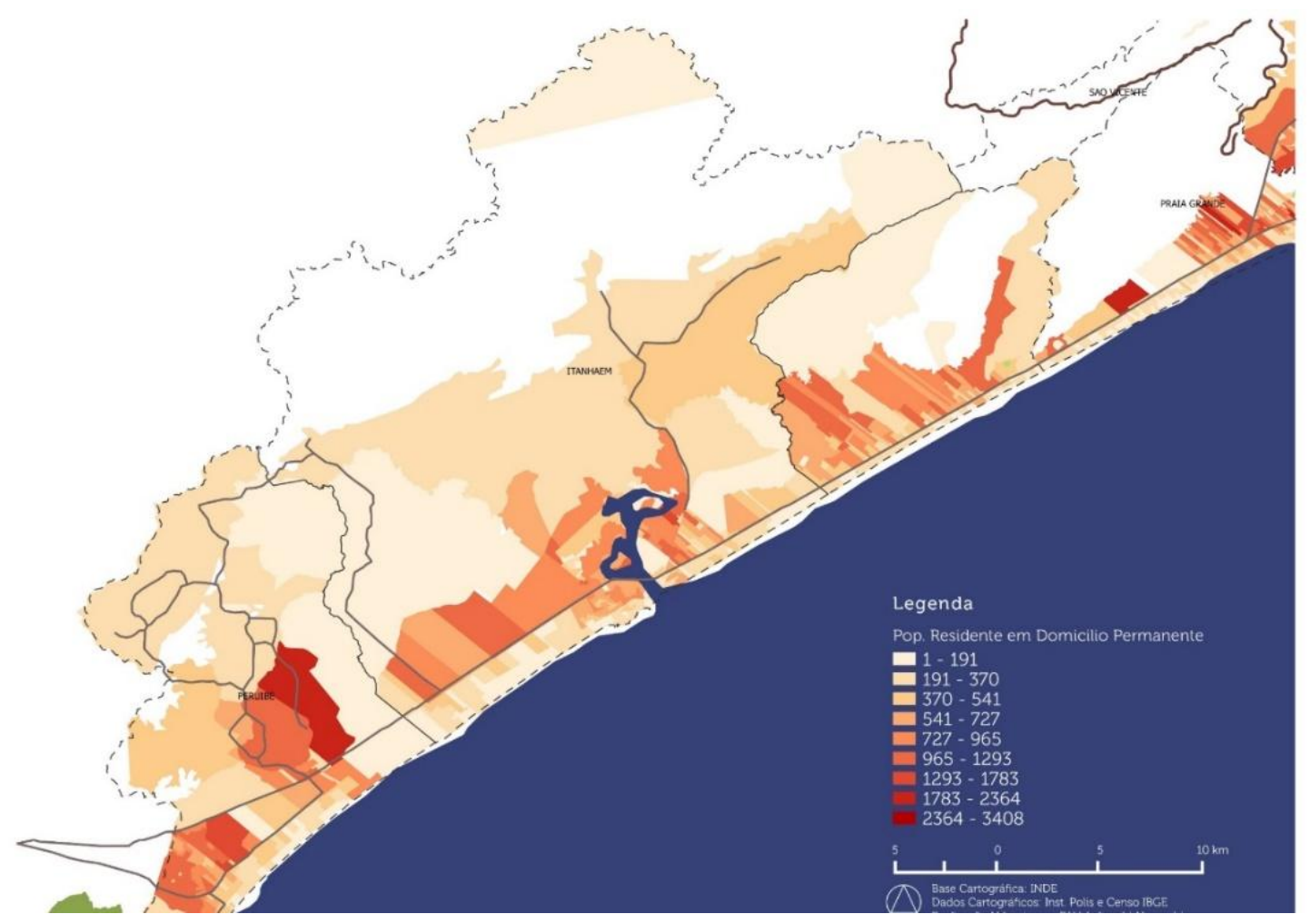

FONTE: Mapa produzido pelos autores.

Como consequência da valorização da praia como espaço de lazer, houve a valorização da terra urbana próxima à orla, onde se percebe um vetor de valorização imobiliária que margeia o trecho Sul da RMBS, atingindo o seu ápice na Praia Grande, conforme se constata na figura 4. Neste município, a disputa pela terra urbana levou à verticalização da faixa edificada da orla por muitos quarteirões adentro, retraindo à medida em que se distancia do trecho central da região metropolitana, com declínio em Peruíbe, onde o gabarito ainda é predominantemente horizontal, conforme se observa na figura 6 . 


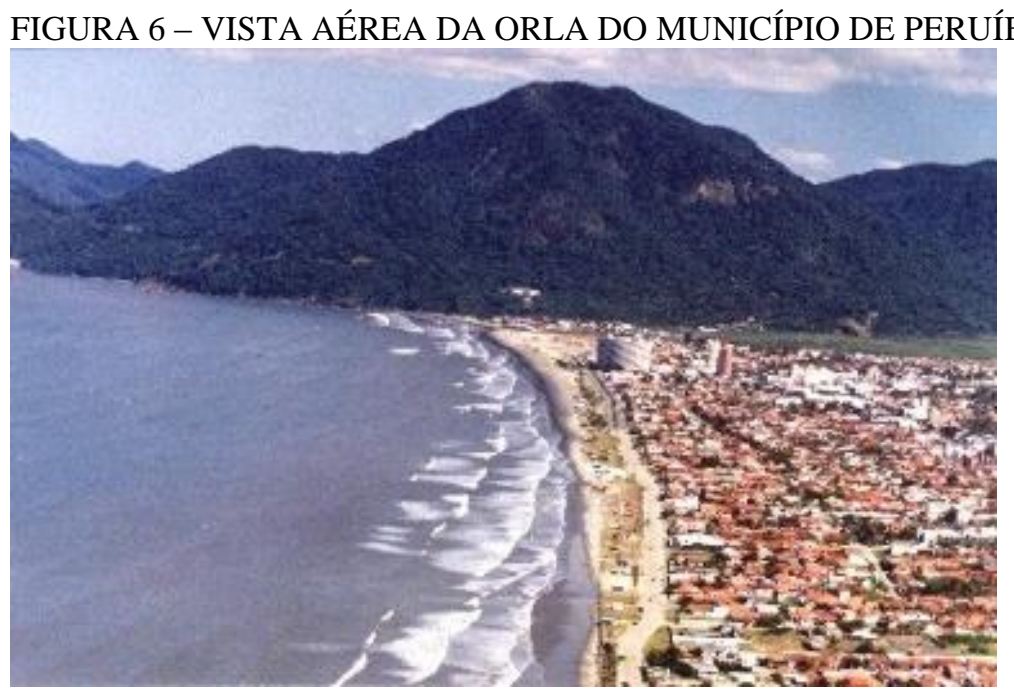

FONTE: Jornal de Peruíbe. Disponível em: <http://www.jornaldeperuibe.com.br/conheca.html>.

O trecho Norte da RMBS, representado na figura 7, repete o padrão de distribuição espacial da população residente e da população flutuante. Em tais espaços a apropriação turística se dá em escala metropolitana, produzindo novas divisões sócio espaciais, uma vez que a valorização da orla marítima, em função de sua proximidade com a praia, encareceu o valor da terra e foi expulsando gradativamente a população residente, dando lugar à população flutuante

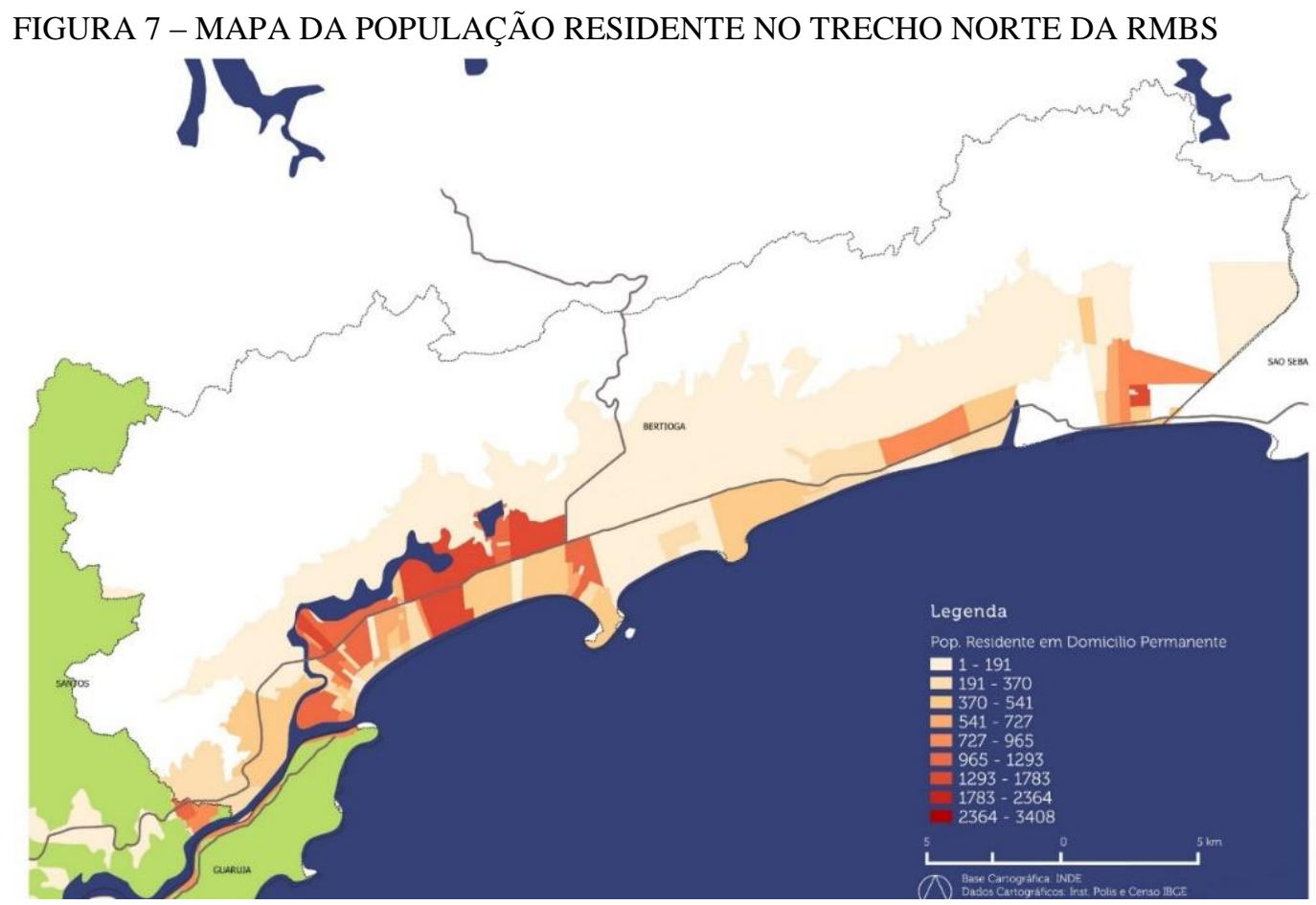

FONTE: Mapa produzido pelos autores Laboratório do Curso de Arquitetura da Universidade Anhembi Morumbi. 
Sobre a apropriação das áreas litorâneas de interesse turístico pela força do mercado imobiliário, Coriolano et al. (2014) afirmam que "a produção do espaço é determinada por relações socioespaciais e de poder", sendo o turismo "uma prática social de apropriação e de dominação de muitos territórios, especialmente nos países tropicais”. O que se verifica na apropriação turística do espaço é que áreas atendem de forma desigual a moradores e turistas, privilegiando aqueles que frequentam os espaços de maior atratividade pelos seus atributos paisagísticos e de infraestrutura, em detrimento dos que ali procuram permanecer a despeito de serem cada vez mais apartados das vantagens naturais e construídas no território.

\section{CONSIDERAÇÕES FINAIS}

A manifestação do turismo sol e praia, característico em toda a costa brasileira, produziu diferentes tipos de paisagens, a partir de aspectos naturais muito diversificados. A apropriação turística destes espaços se deu principalmente em lugares que já dispunham de alguma infraestrutura urbana, principalmente viária, proporcionada por um histórico de desenvolvimento relacionado à exploração dos produtos de interesse comercial, durante o período de colonização.

As mudanças nos hábitos de lazer e recreação da sociedade industrial e a incorporação de um novo uso para a orla marítima produziram uma demanda destes espaços, que anteriormente serviam predominantemente para a pesca e para os transportes marítimos.

Santos e São Vicente foram as primeiras cidades do litoral paulista a passarem por transformações decorrentes do processo de apropriação turística. As ligações entre a baixada santista e o planalto, com infraestrutura de transporte bastante desenvolvida em função da importância da conexão do porto com a região produtora, passaram a comportar também o fluxo turístico entre estas duas regiões. A expansão do turismo pela orla fez com que outras cidades da região despontassem no segmento sol e praia, como Praia Grande, Mongaguá, Itanhaém e Guarujá.

A proximidade do principal centro emissor de turistas - a Região Metropolitana de São Paulo - e a diversificada rede viária entre este e a RMBS, favoreceram uma 
movimentação intensa e frequente entre as duas regiões. O fluxo turístico é considerável nos finais de semana, feriados, aumentando no verão, principalmente durante os meses de férias.

A população flutuante dos municípios da RMBS ocupa os imóveis mais próximos da orla, disputando com a população local a precária infraestrutura viária dos municípios litorâneos, bem como seus locais de abastecimento, hospitais, rede bancária, centros comerciais.

Como contrapartida, o turismo de segunda residência na RMBS oferece oportunidades restritas de trabalho e renda, concentrando seus empregos em ocupações voltadas à manutenção e serviços para os imóveis de uso ocasional.

A segregação espacial, o favorecimento da infraestrutura urbana nas áreas de maior atratividade turística, em detrimento da população local têm gerado situações conflituosas entre as sociedades locais e turistas, o que requer um olhar mais atento para as relações socioespaciais que vêm se estabelecendo na região.

\section{REFERÊNCIAS}

AGEM. Agência Metropolitana da Baixada Santista. Disponível em: <http://www.agem.sp.gov.br/>.

BUENO, E. Capitães do Brasil. São Paulo: Objetiva, 1999.

CEM ANOS DE REPÚBLICA. Um retrato ilustrado da História do Brasil. V. 1. São Paulo: Ed. Nova Cultural, 1989.

CORBIN, A. Território do Vazio: A praia e o imaginário ocidental. São Paulo: Companhia das Letras, 1989.

CORIOLANO, L. N.; MELLO E SILVA, S. B. Turismo: prática social de apropriação e dominação de territórios. In: O turismo e a relação sociedade-natureza - realidades, conflitos e resistências. CORIOLANO, L. N.; VASCONCELOS, F. P. (Org.). 2. ed. Fortaleza: EdUECE, 2014, p. 46 -58.

CRUZ, R. C. A. Introdução à Geografia do Turismo. 2. ed. São Paulo: Rocca, 2003.

DIEGUES, A. C. Ilhas e Mares: Simbolismo e imaginário. São Paulo: Hucitec, 1998.

EMPLASA. Empresa Paulista de Planejamento Metropolitano S/A. Disponível em: $<$ https://www.emplasa.sp.gov.br/RMBS >. 
GASPAR, C. B. Orla Carioca: História e Cultural. São Paulo: Metalivros, 2004.

HOLLANDA, S. B. Raízes do Brasil. 26. ed. São Paulo: Companhia das Letras, 1982.

IBGE. Instituto Brasileiro de Geografia e Estatística. Censos 2010: uma síntese das etapas das pesquisas. Rio de Janeiro: [s. n.].

INDE. Infraestrutura Nacional de Dados Espaciais. Disponível em: $<$ http://www.inde.gov.br/>.

INSTITUTO PÓLIS. Agendas de desenvolvimento sustentável: contribuições para a Baixada Santista e Litoral Norte de São Paulo. Coord.: Nelson Saule Jr. e outros. São Paulo: Instituto Pólis, 2014.

IPEA. Instituto de Pesquisa Econômica Aplicada. Brasil em desenvolvimento 2011: Estado, planejamento e políticas públicas. Brasília: IPEA. 2012.

LEFEBVRE, H. O direito à cidade. São Paulo: Ed. Moraes, 1991.

MACHADO, H. C. F. A construção social da praia. Sociedade e Cultura 1. Cadernos do Nordeste, Série Sociologia, v. 13 (1), p. 201-218, 2000.

MENDES, D. A Calçada do Lorena: o caminho de tropeiros para o comércio do açúcar paulista. Dissertação de Mestrado, Faculdade de Filosofia, Letras e Ciências Humanas da Universidade de São Paulo - FFLCH/USP. 2005.

MTUR. MINISTÉRIO DO TURISMO. Marcos Conceituais. 2010. Disponível em: <http://www.turismo.gov.br/turismo/o_ministerio/publicacoes/cadernos_publicacoes/14 manuais.html>. Acesso em: 12/06/2016.

NEPO. Núcleo de Estudos de População - NEPO/Unicamp. Vulnerabilidade da Região Metropolitana da Baixada Santista. 2009. Disponível em: <http://www.nepo.unicamp.br/vulnerabilidade/sumario/sumario_final_RMBS/index.ht ml>. Acesso em: 12/6/2016.

PAULA, D. A. Estado, sociedade civil e hegemonia do rodoviarismo no Brasil. Revista Brasileira de História da Ciência, Rio de Janeiro, v. 3, n. 2, p. 142-156, 2010.

RAMOS, D. R. A Invenção da Praia e a Produção do Espaço: Dinâmicas de Uso e Ocupação do Litoral do ES. Vitória: Programa de Pós-graduação em Arquitetura e Urbanismo da Universidade Federal do Espírito Santo - UFES, 2009.

SCHUSSEL, Z. G. L. Turismo, Desenvolvimento e Meio Ambiente. In: BRASILEIRO, M. D. S.; MEDINA, J. C. C.; CORIOLANO, L. N. (Orgs.) Turismo, cultura e desenvolvimento [online]. Campina grande: EDUEPB, 2012, 233 p. Disponível em: $<$ SciELO Books <http://books.scielo.org>. 
SILVA, K. O. A territorialização da residência secundária no litoral de Nísia Floresta (Rio Grande do Norte, Brasil). Turismo \& Sociedade. Curitiba, v. 6, n. 1, p. 58-78, 2013.

VIANA, M. F. Com vista para o mar: sobre a produção da imagem da Fortaleza vendável (Ceará, Brasil). Turismo \& Sociedade. Curitiba, v. 5, n. 1, p. 37-57, 2012.

Recebido em: 13-11-2016.

Aprovado em: 13-12-2016. 